\section{An Evaluation of Fertility in Arkansas Primocane-fruiting Blackberries}

\author{
Alisha L. Ruple, John R. Clark ${ }^{\mathbf{1}}$, and M. Elena Garcia \\ Department of Horticulture, University of Arkansas, 316 Plant Science, \\ Fayetteville, AR 72701
}

Additional index words. Rubus, small fruit breeding, pollen viability, self-fertility

\begin{abstract}
Floral fertility of five primocane-fruiting (PF) blackberry (Rubus L. subgenus Rubus Watson) genotypes ('Prime-Jim' ${ }^{\circledR}$, APF-31, 'Prime-Ark ${ }^{\circledR} 45$ ', APF-59, and APF77) and three floricane-fruiting (FF) genotypes ('Navaho', 'Natchez', and 'Ouachita') were tested under field conditions using floricane flowers with four pollination treatments: undisturbed open-pollinated, emasculated self-pollinated, emasculated and cross-pollinated with pollen from a similar fruiting type $(\mathrm{PF} \times \mathrm{PF}$ or $\mathrm{FF} \times \mathrm{FF})$, and emasculated and cross-pollinated with pollen from a different fruiting type $(\mathrm{PF} \times \mathrm{FF}$ or FF $\times$ PF). During primocane flowering, three pollination treatments (undisturbed openpollinated, emasculated selfed, and emasculated cross-pollinated) were used to further test the fertility of the five PF genotypes. Significant differences between cross-pollination treatments and self-pollination were seldom noted with more differences seen in 'Prime$\mathrm{Jim}^{\circledR}{ }^{\circledR}$ than any other genotype. Cross-pollinating primocane flowers on 'Prime-Jim' ${ }^{\circledR}$ resulted in significantly higher fruit set, drupelet set, and average berry weight compared with self-pollination. Fruit set among genotypes ranged from 68.5 to $96.7 \%$, and drupelet set rating ranged from 4.3 to 6.9 for floricane flowers. For open-pollinated primocane flowers, fruit set ranged from 63.9 to $92.1 \%$, and drupelet set rating ranged from 4.3 to 7.2. The genotypes APF-31, APF-59, and APF-77 showed a marked improvement over 'Prime-Jim, ${ }^{\circledR}$ in both percent fruit set and drupelet set of floricane and primocane flowers. The results indicated that fertility appears to be sufficient in all the genotypes evaluated and that the later-generation PF genotypes show improvement in fertility over 'Prime-Jim, ${ }^{\circledR}$. Pollen viability (using both chemical viability testing and in vitro germination testing), stigma receptivity, and pollen tube growth (using florescence) were evaluated in a controlled environment to determine if any improvements could be noticed when comparing a selection of later-generation PF genotypes (APF-31,' Prime-Ark ${ }^{\circledR}$ 45', APF-59, and APF-77) with 'Prime-Jim' ${ }^{\circledR}$ and 'Prime-Jan' ${ }^{\circledR}$. Genotypes APF-31, APF-59, and APF-77 had significantly more viable pollen and pollen germination than 'PrimeJan $^{\circledR}$. Stigma receptivity was observed in all genotypes. Pollen tube growth did not appear to be inhibited after self-pollination in any genotype studied, although significantly greater florescence resulting from pollen tube growth was seen after crosspollination compared with self-pollination for APF-59. There were no significant differences in pollen tube growth between cross- and self-pollination for any other genotype.
\end{abstract}

In 2004, Clark et al. released the first commercial primocane-fruiting (PF) blackberry cultivars, Prime-Jan ${ }^{\circledR}$ (cv. APF-8) and Prime-Jim ${ }^{\circledR}$ (cv. APF-12) (Clark et al., 2005). 'Prime-Ark ${ }^{\circledR} 45$ ' (cv. APF-45) followed in 2009 (University of Arkansas, 2010). 'PrimeJim ${ }^{\circledR}$ and 'Prime-Jan, ${ }^{\circledR}$ have had some production limitations. Both cultivars have exhibited poor summer heat tolerance in field trials (Clark et al., 2005; Drake and Clark, 2003) and controlled-environment studies (Stanton, 2005), resulting in low berry weight, crumbly berries, and poor flavor. Self-incompatibility was also thought to be a factor in fruit set (J.R. Clark, personal communication).

Stanton et al. (2007) concluded that high temperatures $\left(35.0 / 23.9{ }^{\circ} \mathrm{C}\right.$ day/night $)$ in-

Received for publication 4 Dec. 2009. Accepted for publication 26 Apr. 2010.

${ }^{1}$ To whom reprint requests should be addressed; e-mail jrclark@uark.edu. pollinated A-593. Although cross-pollination was superior to self-pollination, fruit set and weight were still lower than the other genotypes in the study, implying that low fertility was a problem for A-593 (Perry, 1981; Perry and Moore, 1985). Because A-593 was a foundational parent in the Arkansas PF blackberry breeding effort and is found in the pedigree of all released and potential releases from the program, this finding is of note. If this low fertility characteristic was transmitted to PF genotypes, this could become an issue if these cultivars or subsequent PF genotypes are grown in solid blocks where other sources of pollen are not available. There is a need to evaluate fertility in 'Prime-Jim' ${ }^{\circledR}$ and 'Prime-Jan' ${ }^{\circledR}$ as well as in subsequent generations that are believed to have better fruit set and heat tolerance based on field observations between 2005 and 2007. Some commercially important thornless floricane-fruiting (FF) cultivars also need to be evaluated because the fertility of each has not been thoroughly assessed.

The objectives of this study were to: 1) evaluate the effects of self- and crosspollination on floricane and primocane fertilization and fruit set among a set of PF and FF genotypes in a field setting; and 2) evaluate different components of flower fertility in a controlled environment.

\section{Materials and Methods}

Field evaluation of fertility. This study was conducted at the Fruit Research Station, Clarksville, AR (lat. 35 $31^{\prime \prime} 58^{\prime} \mathrm{N}$ and long. $93^{\circ} 24^{\prime \prime} 2^{\prime} \mathrm{W}$ ). Five PF genotypes ('Prime-

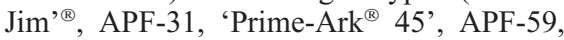
and APF-77) and three FF genotypes ('Navaho', 'Natchez', and 'Ouachita') within the University of Arkansas breeding program were evaluated. The genotypes APF-31, 'Prime-Ark ${ }^{\circledR}$ 45', APF-59, and APF-77 are later-generation developments than PrimeJan ${ }^{\circledR}$ and 'Prime-Jim' ${ }^{\circledR}$. The unreplicated field plots used for the study varied in age as a result of timing of selection within the breeding program and were $6 \mathrm{~m}$ in length with canes filling the plot.

Four pollination treatments were applied to floricane flowers in Spring 2008: 1) undisturbed open; 2) emasculated self; 3) emasculated and cross-pollinated with pollen from a similar fruiting type $(\mathrm{PF} \times \mathrm{PF}, \mathrm{FF} \times \mathrm{FF})$; and 4) emasculated and cross-pollinated with pollen from a different fruiting type $(\mathrm{PF} \times \mathrm{FF}$, $\mathrm{FF} \times \mathrm{PF})($ Table 1). Each treatment was applied to five to 10 flowers in a single inflorescence in each replication with a total of 10 replications; a minimum of 50 total flowers per treatment combination was used. Inflorescences were chosen based on bud number before bud break; leaves that obstructed access to buds or prevented bags from fitting over inflorescence were removed and then inflorescences to be used for self- or cross-pollination were covered with a protective bag (\#421; Lawson Pollinating Bags, Northfield, IL) (Daubeny, 1996). Bags were checked every 2 to $3 \mathrm{~d}$ for buds approaching 
Breeding, Cultivars, Rootstocks, and Germplasm Resources

Table 1. Sources for pollen used in various pollination treatments for blackberry genotypes in a field study using floricane and primocane flowers.

\begin{tabular}{|c|c|c|c|c|}
\hline \multirow[b]{2}{*}{ Genotypes } & \multicolumn{4}{|c|}{ Pollination treatments } \\
\hline & Open-pollination & Self-pollenizer & Similar genotype cross-pollenizer ${ }^{z}$ & Different genotype cross-pollenizer \\
\hline APF-31 & Unknown & APF-31 & APF-77 & Natchez \\
\hline Prime-Ark ${ }^{\circledR} 45$ & Unknown & Prime-Ark ${ }^{\circledR} 45$ & APF-31 & Natchez \\
\hline APF-59 & Unknown & APF-59 & APF-31 & Natchez \\
\hline APF-77 & Unknown & APF-77 & APF-31 & Natchez \\
\hline Prime-Jim ${ }^{\circledR}$ & Unknown & Prime-Jim ${ }^{\circledR}$ & APF-31 & Natchez \\
\hline Natchez & Unknown & Natchez & Ouachita & APF-31 \\
\hline Navaho & Unknown & Navaho & Natchez & APF-31 \\
\hline Ouachita & Unknown & Ouachita & Natchez & APF-31 \\
\hline
\end{tabular}

${ }^{\mathrm{z}}$ Cross-pollenizers chosen based on pollen production and quality of fruit set in field observations, and APF-31 and APF-77 share one common parent.

petal break. Once the calyx began to separate, allowing petals to be visible, flowers were emasculated using a scalpel to cut along the base of the bud between the torus and calyx. The calyx, corolla, and all anthers were removed, leaving only the pistils. Each flower was pollinated once by brushing pollen on all pistils 1 to $3 \mathrm{~d}$ after emasculation (when styles were separated and receptive) and then tagged. Open-pollinated flowers were tagged when flowers reached full size but before petals began to separate.

Pollen was collected from the same plots receiving pollination treatments based on the sequence of flowering of the genotypes. Pollen was collected using methods outlined by Galletta (1983) and Layne (1983). Pollination of floricanes began on 23 Apr. 2008 and concluded 12 June 2008; harvest began 6 June 2008 and was completed 21 July 2008. Cool temperatures and frequent rain characterized the fruit development period. Disease (causal agent unknown) was noted on 'Prime$\mathrm{Ark}^{\circledR} 45$ ', 'Prime-Jim' ${ }^{\circledR}$, and 'Natchez'. This disease accounted for the loss of numerous flowers. Average maximum temperatures for April, May, and June were 19.8, 24.3, and $28.2{ }^{\circ} \mathrm{C}$, respectively, although the first part of June (when pollinations were completed) had temperatures more similar to May because the latter part of the month was warmer.

Five PF genotypes were evaluated during the primocane season: 'Prime-Jim ${ }^{\circledR}$, APF31, 'Prime-Ark ${ }^{\circledR} 45$ ', APF-59, and APF-77. Three pollination treatments were applied to primocane flowers in Summer 2008 using the same methods used on floricane flowers: undisturbed open, emasculated self, and emasculated cross-pollination with pollen from a similar-fruiting type $(\mathrm{PF} \times \mathrm{PF})($ Table 1). Primocane pollen was collected in a similar fashion as floricane pollen. Pollination of primocanes began on 7 July 2008 and concluded 5 Aug. 2008; harvest began 11 Aug. 2008 and was completed 9 Sept. 2008. Average maximum temperatures for July and August were 31.8 and $29.8{ }^{\circ} \mathrm{C}$, respectively, substantially higher than the floricane flowering period.

Measurements taken during both flowering seasons included: percent fruit set (number of fruit/number of flowers pollinated), visual rating of drupelet set (subjective rating scale of 0 to $9 ; 0=$ berries with no drupelets set, $1=$ less than $20 \%$ drupelets appeared to have fully formed, $2=20 \%$ to $29 \%, 3=30 \%$ to $39 \%, 4=40 \%$ to $49 \%, 5=50 \%$ to $59 \%, 6=$ $60 \%$ to $69 \%, 7=70 \%$ to $79 \%, 8=80 \%$ to $89 \%$, and $9=90 \%$ or greater), and berry weight. Drupelet set was estimated rather than counted as a result of the large sample size. Berry weight for berries with a visual drupelet set rating of " 0 " was counted as missing data. All berries with a visual drupelet set rating greater than " 0 " were averaged together within a genotype or treatment, and the incidence of berries with very poor drupelet set reduced the average weight.

Floricane and primocane results were analyzed separately because the genotypes and pollination treatments used for each study were not identical. SAS 9.2 (SAS Institute, 2008) was used for all statistical analyses. The experimental unit was an inflorescence. Proportions were compared within the variable percent fruit set using logit analysis. Before implementing logit analysis, the FREQ procedure was used to confirm that the distribution of zeros was independent of genotype and pollination method. Replications with no flowers set were treated as missing data for percent fruit set. Means were separated using a single df contrast. Two-way analysis of variance (ANOVA), using genotype and pollination treatment as factors, was used to compare means for visual rating of drupelet set and berry weight. Means were separated using Fisher's protected least significant difference (LSD).

Evaluation of fertility components in a controlled environment. This study was conducted in a greenhouse located at the Arkansas Agricultural Research and Extension Center (AAREC), Fayetteville, AR (lat. $36^{\circ} 5^{\prime \prime} 47^{\prime} \mathrm{N}$, long. $94^{\circ} 10^{\prime \prime} 29^{\prime} \mathrm{W}$ ). Four elements of fertility [pollen viability, pollen germination, stigma receptivity, and pollen tube growth (increase in length down style)] were evaluated on six PF genotypes: 'PrimeJim $^{(\circledR}$, 'Prime-Jan' ${ }^{\circledR}$, APF-31, 'Prime-Ark ${ }^{\circledR}$ 45', APF-59, and APF-77. In Feb. 2008, five plants from each genotype were dug from the blackberry breeding field at the Fruit Research Station and transplanted into 20-L pots containing Sunshine Professional Growing Mix (Sun Gro, Bellevue, WA.). Potted plants were watered as needed and fertilized every 2 weeks with 1 L 20-10-20 Peters Professional Water-Soluble Fertilizer (Scotts Sierra Horticultural Products Co., Marysville, $\mathrm{OH})$. Plants remained under $30 \%$ shade at Clarksville until Sept. 2008 when they were moved to the AAREC and placed under $30 \%$ shade. In late Nov. 2008, plants were placed in a cold frame and covered with mulch. After 6 weeks of cold exposure to meet dormancy requirements, plants were arranged in an unshaded greenhouse in five randomized complete blocks. Daily minimum temperature was $18{ }^{\circ} \mathrm{C}$ with maximum temperature of $27{ }^{\circ} \mathrm{C}$. Data collection began in late Jan. 2009 when floricanes began flowering.

Pollen viability. One to two flowers were harvested for pollen collection when the calyx was beginning to separate. Pollen was collected in the same manner as in the field study. A small brush was used to gather pollen from the sides of the vial and then tapped over a microscope slide to dislodge pollen onto the slide. One to two drops of aniline blue stain were placed on top of the pollen, and samples were covered and allowed to stain at least $10 \mathrm{~min}$ (Kearns and Inouye, 1993). Samples were viewed under a light microscope and 500 pollen grains were counted with stained pollen grains noted. Pollen grains were classified as either viable or nonviable based on staining. This procedure was replicated five times.

Pollen germination. Pollen from one to two flowers was collected using methods previously described. Pollen was gathered from the sides of a vial containing a single pollen sample with a small brush, which was then tapped to dislodge pollen onto a petri dish containing Brewbaker \& Kwack's medium. The petri dish was sealed with parafilm "M" ${ }^{\circledR}$ (Pechiney Plastic Packaging, Chicago, IL) and then incubated at room temperature $\left(23^{\circ} \mathrm{C}\right)$ for $48 \mathrm{~h}$. After incubation, plates were examined under a light microscope, and 500 pollen grains were counted, noting germinated grains (Kearns and Inouye, 1993). Pollen grains were counted as germinated if the pollen tube was at least as long as the diameter of the grain. This procedure was replicated five times.

Stigma receptivity. During preliminary tests in Fall 2008, it was noted that viewing of the interaction between guaiacol solution and peroxidase was hindered by the presence of anthers and petals. Therefore, 25 flowers per genotype (five flowers per plant, representing one replication) were emasculated when calyxes began to separate. Beginning $1 \mathrm{~d}$ after emasculation, $\approx 1 \mu \mathrm{L}$ of guaiacol solution was applied to the stigmas using a cotton swab. Guaiacol solution was applied 
every $24 \mathrm{~h}$ until stigmas were receptive or began to senesce (Stanton, 2005). Receptivity was indicated by a change in color from light green to reddish brown.

Pollen tube growth. Pollen tube growth was evaluated after four pollination treatments [open, self, similar-fruiting-type cross $(\mathrm{PF} \times \mathrm{PF})$, and unpollinated control] had been applied to four to five flowers per genotype. A small brush was used to stir anthers within flowers to ensure ample pollination in flowers selected for open-pollination. When buds began to show petal break, flowers used for self- or cross-pollination were emasculated, leaving only the pistil aggregate. Pistil aggregates were collected from plants $48 \mathrm{~h}$ after pollination had occurred. Flower buds used as the unpollinated checks were not emasculated until after buds had been collected from plants.

Collected pistil aggregates were fixed immediately in 1:8:1 formalin:ethanol:acetic acid solution for $24 \mathrm{~h}$. After a rinse with distilled water, pistils were macerated in sodium hydroxide $(8 \mathrm{~N})$ for $24 \mathrm{~h}$. A 24 -h soak in distilled water followed. Pistils were then placed in a $0.1 \%$ solution of aniline blue dye in $0.1 \mathrm{M}$ tribasic $\mathrm{K}_{3} \mathrm{PO}_{4}$ for $4 \mathrm{~h}$, mounted on a slide in a few drops of glycerine to prevent drying, gently squashed, and observed immediately under an ultraviolet microscope (Kearns and Inouye, 1993; Perry, 1981). Digital images were taken of 35 randomly selected pistils per genotype per pollination treatment. Pollen tubes were too numerous and miniscule to be counted and measured individually. Rather, fluorescence appearing in digital images was rated on a 0 to 4 scale in which $0=$ no fluorescence and $4=$ bright fluorescence throughout the length and width of the style (Fig. 1).
SAS 9.2 (SAS Institute, 2008) was used for statistical analyses. Data from pollen viability and germination tests were analyzed by one-way ANOVA using the MIXED procedure. Statistical analysis was not conducted on stigmatic receptivity data because of the high percentage of replications showing $100 \%$ fully receptive stigmas. Two-way ANOVA, factoring genotype and pollination treatment and using the MIXED procedure, was used to analyze data concerning pollen tube growth. All means were separated by Fisher's protected LSD.

\section{Results}

Field evaluation of fertility using floricane flowers. Genotypes differed for fruit set $(P<0.0001)$, berry weight $(P<0.0001)$, and visual rating of drupelet set $(P<0.0001)$. Pollination treatment had a main effect on fruit set $(P=0.0110)$, berry weight $(P<$ $0.0001)$, and visual rating of drupelet set $(P<0.0001)$. The interactions between genotype and pollination treatment were not significant.

'Navaho' and APF-59 set the greatest percentage of fruit $(97 \%$ and $92 \%$, respectively); among PF genotypes, 'Prime-Jim' ${ }^{\text {(B) }}$ had the lowest percentage of fruit set (Table 2 ). Fruit set among pollination treatments ranged from $92 \%$ (open-pollination) to $83 \%$ (self-pollination) (Table 3).

Berry weights for APF-31 and APF-59 were significantly larger than the other six genotypes, whereas APF-77, 'Navaho', and 'Ouachita' had the smallest berries (Table 2). Among pollination treatments, open-pollinated berries were significantly larger than the other three pollination treatments, which were statistically similar (Table 3 ).

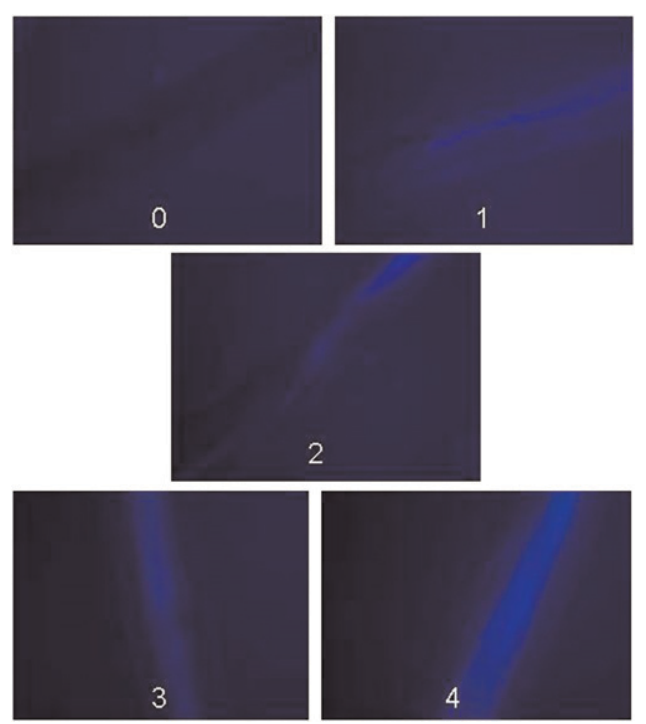

Fig. 1. Styles of primocane-fruiting blackberry flowers viewed under an ultraviolet light microscope. A subjective rating system ( 0 to 4 ) used to assess the amount of fluorescence present in the style; $0=$ no fluorescence visible within the style, $1=$ minimal fluorescence noted in the style, $2=$ style full of fluorescence in upper half with no fluorescence noted in the over half, 3 = fluorescence noted down the entire length of style but not filling the entire width of the style, and $4=$ fluorescence noted down the entire length and width of the style.

Within drupelet set rating, open-pollinated berries had significantly higher drupelet set than the other three pollination treatments, which were statistically similar (Table 3 ). Among all genotypes, 'Prime-Ark ${ }^{\circledR} 45$ ', APF-31, and APF-77 had the greatest average ratings $(6.9,6.7$, and 6.3 , respectively), whereas 'Prime-Jim' ${ }^{\circledR}$ had the lowest average rating, significantly lower than the five other PF genotypes (Table 2).

Field evaluation of fertility using primocane flowers. The interactions between genotype and pollination treatment were significant for percent fruit set $(P=0.0428)$, berry weight $(P=0.0011)$, and rating of drupelet set $(P=0.0014)$.

Percent fruit set ranged from $3.3 \%$ to $92.1 \%$ (Table 4 ). A significantly greater percentage of flowers set after open-pollination compared with cross- or self-pollination for APF-31, 'Prime-Ark ${ }^{\circledR}$ 45', APF-59, and APF-77. Cross- and self-pollination did not differ for these genotypes. Self-pollination resulted in the lowest fruit set for 'PrimeJim ${ }^{\circledR}$, being significantly less than both cross- and open-pollination.

Average berry weight ranged from 1.2 to $4.7 \mathrm{~g}$ (Table 4). Cross-pollination resulted in significantly heavier berries than selfpollination for 'Prime-Ark ${ }^{\circledR} 45^{\prime}$ ' and 'Prime$\mathrm{Jim}^{\circledR}{ }^{\circledR}$, but there were no significant differences for APF-31, APF-59, and APF-77. Open-pollinated berries weighed significantly more than cross- or self-pollinated berries for APF-31, APF-59, and APF-77.

APF-77 open-pollinated berries had the highest rating of drupelet set followed closely by APF-31 open-pollinated berries ( 7.2 and 7.0, respectively) (Table 4). Significantly greater drupelet set was recorded after crosspollination compared with self-pollination for APF-59 and 'Prime-Jim' ${ }^{\circledR}$, but no difference was noted for APF-31, 'Prime-Ark ${ }^{\circledR} 45$ ', or APF-77. Drupelet set after open-pollination was significantly higher compared with crossand self-pollination for APF-31, 'Prime-Ark' ${ }^{\text {(B) }}$ 45, APF-59, and APF-77, but did not differ from cross-pollination for 'Prime-Jim' ${ }^{\circledR}$.

Evaluation of fertility components in a controlled environment. Genotypes differed for pollen viability $(P=0.0189)$ and pollen germination $(P<0.0001)$. Pollen viability ranged from $76.0 \%$ to $89.3 \%$ among genotypes. APF-31, APF-77, and APF-59 had significantly more viable pollen than 'PrimeJan' ${ }^{\circledR}$ (Table 5). Percent pollen germination ranged from $8.5 \%$ to $17.5 \%$ among genotypes (Table 5). Significantly more pollen germinated for APF-31, APF-59, and APF-77 than for 'Prime-Jim' ${ }^{\circledR}$ and 'Prime-Jan' ${ }^{\circledR}$.

We observed that the strength of the reaction between guaiacol solution and peroxidase on receptive stigmas (based on color intensity) varied among flowers as did the timing of receptivity after emasculation. Also, the stigmas at the tip of an aggregate were receptive before the stigmas closer to the base of the aggregate. This pattern is analogous to the pattern of drupelet ripening proceeding from the tip of a berry toward the base. Receptive stigmas were noted on every 
Table 2. Main effect of genotype on percent fruit set, average berry weight, and average drupelet set rating in blackberry floricane flowers in a field setting.

\begin{tabular}{|c|c|c|c|}
\hline Genotype & Fruit set $(\%)$ & Avg berry wt $(\mathrm{g})$ & Avg drupelet set rating $(0-9)^{2}$ \\
\hline$\overline{\mathrm{APF}-31}$ & $88.2 \mathrm{bc}^{y}$ & $3.8 \mathrm{a}^{\mathrm{x}}$ & $6.7 a^{x}$ \\
\hline Prime-Ark ${ }^{\circledR} 45$ & $91.0 \mathrm{~b}$ & $2.7 \mathrm{bcd}$ & $6.9 \mathrm{a}$ \\
\hline APF-59 & $92.1 \mathrm{ab}$ & $3.6 \mathrm{a}$ & $6.2 \mathrm{bcd}$ \\
\hline APF-77 & $90.0 \mathrm{bc}$ & 2.4 cde & $6.3 \mathrm{abc}$ \\
\hline Prime-Jim ${ }^{\circledR}$ & $68.5 \mathrm{~d}$ & $2.9 \mathrm{~b}$ & $4.3 \mathrm{e}$ \\
\hline Natchez & $77.4 \mathrm{~d}$ & $2.7 \mathrm{bc}$ & $4.7 \mathrm{e}$ \\
\hline Navaho & $96.7 \mathrm{a}$ & $2.1 \mathrm{e}$ & $5.9 \mathrm{bcd}$ \\
\hline Ouachita & $80.7 \mathrm{~cd}$ & $2.2 \mathrm{e}$ & $5.0 \mathrm{e}$ \\
\hline
\end{tabular}

${ }^{{ }^{2}}$ Subjective rating system; $0=$ berries with no drupelets set, $1=$ less than $20 \%$ drupelets appeared to have fully formed, $2=20 \%$ to $29 \%, 3=30 \%$ to $39 \%, 4=40 \%$ to $49 \%, 5=50 \%$ to $59 \%, 6=60 \%$ to $69 \%, 7=70 \%$ to $79 \%, 8=80 \%$ to $89 \%$, and $9=$ greater than $90 \%$.

'Percentages followed by the same letter are not significantly different at $\alpha=0.05$; means separated by single df contrast.

${ }^{x}$ Means followed by the same letter are not significantly different at $\alpha=0.05$; separated by Fisher's protected least significant difference.

Table 3. Main effect of pollination treatment on percent fruit set, average berry weight, and average drupelet set rating in blackberry floricane flowers in a field setting.

\begin{tabular}{lccc}
\hline Pollination treatment & Fruit set (\%) & Avg berry wt (g) & Avg drupelet set rating $(0-9)^{z}$ \\
\hline Open & $92.4 \mathrm{a}^{\mathrm{y}}$ & $3.9 \mathrm{a}^{\mathrm{x}}$ & $7.2 \mathrm{a}^{\mathrm{x}}$ \\
$\mathrm{PF} \times \mathrm{FF}$ or FF $\times$ PF & $86.1 \mathrm{~b}$ & $2.5 \mathrm{~b}$ & $5.2 \mathrm{~b}$ \\
$\mathrm{PF} \times \mathrm{PF}$ or FF $\times$ FF & $88.1 \mathrm{ab}$ & $2.3 \mathrm{~b}$ & $5.3 \mathrm{~b}$ \\
Self & $82.8 \mathrm{~b}$ & $2.5 \mathrm{~b}$ & $5.3 \mathrm{~b}$ \\
\hline
\end{tabular}

${ }^{2}$ Subjective rating system; $0=$ berries with no drupelets set, $1=$ less than $20 \%$ drupelets appeared to have fully formed, $2=20 \%$ to $29 \%, 3=30 \%$ to $39 \%, 4=40 \%$ to $49 \%, 5=50 \%$ to $59 \%, 6=60 \%$ to $69 \%, 7=70 \%$ to $79 \%, 8=80 \%$ to $89 \%$, and $9=$ greater than $90 \%$.

${ }^{\text {y}}$ Percentages followed by the same letter are not significantly different at $\alpha=0.05$; means separated by single df contrast.

${ }^{\mathrm{x}}$ Means followed by the same letter are not significantly different at $\alpha=0.05$; separated by Fisher's protected least significant difference.

$\mathrm{PF}=$ primocane-fruiting; $\mathrm{FF}=$ floricane-fruiting.

Table 4. Interaction effects of genotype and pollination treatment on percent fruit set, average berry weight, and average drupelet set rating for blackberry primocane flowers grown in a field setting.

\begin{tabular}{|c|c|c|c|c|}
\hline Genotype & $\begin{array}{c}\text { Pollination } \\
\text { treatment }\end{array}$ & $\begin{array}{c}\text { Fruit } \\
\text { set }(\%)\end{array}$ & $\begin{array}{l}\text { Avg berry } \\
\text { wt (g) }\end{array}$ & $\begin{array}{l}\text { Avg drupelet } \\
\text { set rating }(0-9)^{z}\end{array}$ \\
\hline$\overline{\mathrm{APF}-31}$ & Open & $92.1 \mathrm{a}^{y}$ & $4.2 \mathrm{a}^{\mathrm{x}}$ & $7.0 \mathrm{a}^{\mathrm{x}}$ \\
\hline APF-31 & Cross & $38.3 \mathrm{~b}$ & $1.2 \mathrm{~b}$ & $1.7 \mathrm{~b}$ \\
\hline APF-31 & Self & $43.3 \mathrm{~b}$ & $1.5 \mathrm{~b}$ & $2.3 \mathrm{~b}$ \\
\hline Prime-Ark ${ }^{\circledR} 45$ & Open & $63.9 \mathrm{a}$ & $2.9 \mathrm{~b}$ & $4.3 \mathrm{a}$ \\
\hline Prime-Ark ${ }^{\circledR} 45$ & Cross & $3.3 \mathrm{~b}$ & $4.7 \mathrm{a}$ & $0.3 \mathrm{~b}$ \\
\hline Prime-Ark ${ }^{\circledR} 45$ & Self & $19.6 \mathrm{~b}$ & $1.4 \mathrm{c}$ & $1.1 \mathrm{~b}$ \\
\hline APF-59 & Open & $89.1 \mathrm{a}$ & $4.0 \mathrm{a}$ & $6.3 \mathrm{a}$ \\
\hline APF-59 & Cross & $50.7 \mathrm{~b}$ & $2.0 \mathrm{~b}$ & $3.5 \mathrm{~b}$ \\
\hline APF-59 & Self & $26.7 \mathrm{~b}$ & $1.8 \mathrm{~b}$ & $1.5 \mathrm{c}$ \\
\hline APF-77 & Open & $88.2 \mathrm{a}$ & $4.3 \mathrm{a}$ & $7.2 \mathrm{a}$ \\
\hline APF-77 & Cross & $51.8 \mathrm{~b}$ & $1.6 \mathrm{~b}$ & $3.0 \mathrm{~b}$ \\
\hline APF-77 & Self & $46.7 \mathrm{~b}$ & $2.0 \mathrm{~b}$ & $3.2 \mathrm{~b}$ \\
\hline Prime-Jim ${ }^{\circledR}$ & Open & $75.6 \mathrm{a}$ & $1.9 \mathrm{ab}$ & $4.3 \mathrm{a}$ \\
\hline Prime-Jim ${ }^{\circledR}$ & Cross & $70.7 \mathrm{a}$ & $2.3 \mathrm{a}$ & $4.5 \mathrm{a}$ \\
\hline Prime-Jim ${ }^{\circledR}$ & Self & $40.0 \mathrm{~b}$ & $1.2 \mathrm{~b}$ & $2.1 \mathrm{~b}$ \\
\hline
\end{tabular}

${ }^{\mathrm{z}}$ Subjective rating system; $0=$ berries with no drupelets set, $1=$ less than $20 \%$ drupelets appeared to have fully formed, $2=20 \%$ to $29 \%, 3=30 \%$ to $39 \%, 4=40 \%$ to $49 \%, 5=50 \%$ to $59 \%, 6=60 \%$ to $69 \%, 7=70 \%$ to $79 \%, 8=80 \%$ to $89 \%$, and $9=$ greater than $90 \%$.

'Percentages followed by the same letter are not significantly different at $\alpha=0.05$; means separated by single df contrast.

${ }^{\times}$Means followed by the same letter are not significantly different at $\alpha=0.05$; separated by Fisher's protected least significant difference.

flower tested on APF-31, APF-77, and 'Prime-Jim, ${ }^{\circledR}$. For genotypes 'Prime-Ark ${ }^{\circledR}$ $45^{\prime}$ and APF-59, one flower out of 25 senesced before stigma receptivity was noted. Three flowers senesced before becoming receptive on 'Prime-Jan' ${ }^{\circledR}$.

The interaction between genotype and pollination treatment was significant $(P<$
0.0001) for pollen tube growth (Table 6). The unpollinated checks displayed a low amount of fluorescence, as expected. APF31 and 'Prime-Ark ${ }^{\circledR} 45$ ' showed significantly more fluorescence after both cross- and selfpollination than APF-77, 'Prime-Jim, ${ }^{\circledR}$, and 'Prime-Jan' ${ }^{\circledR}$. APF-59 was the only genotype that exhibited a significantly lower amount of
Table 5. Main effect of genotype on pollen viability and pollen germination using pollen from primocane-fruiting blackberry floricane flowers grown in a controlled environment.

\begin{tabular}{|c|c|c|}
\hline Genotype & $\begin{array}{c}\text { Pollen } \\
\text { viability }(\%)^{z}\end{array}$ & $\begin{array}{c}\text { Pollen } \\
\text { germination }(\%)^{y}\end{array}$ \\
\hline$\overline{\mathrm{APF}}-31$ & $89.3 \mathrm{a}^{\mathrm{x}}$ & $17.5 \mathrm{a}^{\mathrm{x}}$ \\
\hline APF-77 & $89.3 \mathrm{a}$ & $16.8 \mathrm{ab}$ \\
\hline APF-59 & $87.0 \mathrm{a}$ & $13.5 \mathrm{bc}$ \\
\hline Prime-Ark ${ }^{\circledR} 45$ & $83.2 \mathrm{ab}$ & $11.5 \mathrm{~cd}$ \\
\hline Prime Jim $^{\circledR}$ & $81.9 \mathrm{ab}$ & $9.2 \mathrm{~d}$ \\
\hline Prime Jan ${ }^{\circledR}$ & $76.3 \mathrm{~b}$ & $8.5 \mathrm{~d}$ \\
\hline
\end{tabular}

${ }^{\mathrm{z}}$ Measured $24 \mathrm{~h}$ after collection using aniline blue stain.

${ }^{\mathrm{y}}$ Measured after $48 \mathrm{~h}$ incubation on Brewbaker \& Kwack's media.

${ }^{\mathrm{x}}$ Means followed by the same letter are not significantly different at $\alpha=0.05$; separated by Fisher's protected least significant difference.

Table 6. Interaction of genotype and pollination treatment on visual rating of pollen tube fluorescence for floricane flowers from primocane-fruiting blackberries grown in a controlled environment.

\begin{tabular}{|c|c|c|}
\hline Genotype & $\begin{array}{c}\text { Pollination } \\
\text { treatment }\end{array}$ & $\begin{array}{c}\text { Fluorescence } \\
\text { rating }^{z}\end{array}$ \\
\hline$\overline{\mathrm{APF}-31}$ & Open & $1.9 \operatorname{cdef}^{y}$ \\
\hline APF-31 & Self & $2.7 \mathrm{ab}$ \\
\hline APF-31 & Cross & $2.3 \mathrm{bc}$ \\
\hline APF-31 & Unpollinated & 0.0 \\
\hline Prime-Ark ${ }^{\circledR} 45$ & Open & $2.9 \mathrm{a}$ \\
\hline Prime-Ark ${ }^{\circledR} 45$ & Self & $2.6 \mathrm{ab}$ \\
\hline Prime-Ark ${ }^{\circledR} 45$ & Cross & $2.1 \mathrm{bcd}$ \\
\hline Prime-Ark ${ }^{\circledR} 45$ & Unpollinated & $0.5 \mathrm{jkl}$ \\
\hline APF-59 & Open & $1.6 \mathrm{efg}$ \\
\hline APF-59 & Self & $1.4 \mathrm{fgh}$ \\
\hline APF-59 & Cross & 2.0 cde \\
\hline APF-59 & Unpollinated & $0.3 \mathrm{kl}$ \\
\hline APF-77 & Open & $0.8 \mathrm{ijk}$ \\
\hline APF-77 & Self & $1.4 \mathrm{fgh}$ \\
\hline APF-77 & Cross & $1.5 \mathrm{efgh}$ \\
\hline APF-77 & Unpollinated & $0.7 \mathrm{ijk}$ \\
\hline Prime-Jan ${ }^{\circledR}$ & Open & $1.5 \mathrm{efgh}$ \\
\hline Prime-Jan ${ }^{\circledR}$ & Self & $1.4 \mathrm{fgh}$ \\
\hline Prime-Jan ${ }^{\circledR}$ & Cross & $1.1 \mathrm{ghi}$ \\
\hline Prime-Jan ${ }^{\circledR}$ & Unpollinated & 1.0 hij \\
\hline Prime-Jim ${ }^{\circledR}$ & Open & $2.2 \mathrm{bc}$ \\
\hline Prime-Jim ${ }^{\circledR}$ & Self & $1.9 \mathrm{cdef}$ \\
\hline Prime-Jim ${ }^{\circledR}$ & Cross & $1.6 \mathrm{defg}$ \\
\hline Prime-Jim ${ }^{\circledR}$ & Unpollinated & 0.0 \\
\hline
\end{tabular}

${ }^{\mathrm{z}}$ Subjective rating system; $0=$ no fluorescence visible within style, $1=$ minimal fluorescence noted in style, 2 = style full of fluorescence in upper half, with no fluorescence noted in lower half, 3 = fluorescence noted down entire length of style, but not filling entire width of style, and $4=$ fluorescence noted down entire length and width of style.

${ }^{y}$ Means followed by the same letter are not significantly different at $\alpha=0.05$; separated by Fisher's protected least significant difference.

fluorescence resulting from self-pollination compared with the amount resulting from cross-pollination.

\section{Discussion}

The fertility of all eight genotypes, measured by percent fruit set and visual rating of drupelet set, fell within previously established 
adequate levels. Fruit set ranged from $68.5 \%$ to $96.7 \%$, and drupelet set ranged from 4.3 to 6.9 for floricane flowers. Fruit set ranged from $63.9 \%$ to $92.1 \%$, and drupelet set ranged from 4.3 to 7.0 for open-pollinated primocane flowers. Previous work has considered raspberries to have "adequate" fertility if drupelet set ranged between $55.5 \%$ and $74.8 \%$ (Daubeny, 1969, 1971). The later-generation genotypes showed a marked improvement over 'Prime-Jim' ${ }^{\circledR}$ in both percent fruit set and drupelet set of floricane flowers. This was also noted in the primocane flowers of APF31, APF-59, and APF-77, which had greater fruit set, drupelet set, and average berry weight than 'Prime-Jim' ${ }^{\circledR}$.

Cross-pollination did not result in greater fruit set, berry weight, or drupelet set compared with self-pollination in floricane flowers. For most genotype* pollination treatment interactions in primocane flowers, there was not a difference between cross- and selfpollination. However, for 'Prime-Jim, ${ }^{\circledR}$, cross-pollinated primocane flowers resulted in significantly greater fruit set, drupelet set, and average berry weight compared with self-pollination. The results from both growing seasons indicated that fertility of the latergeneration PF genotypes does not improve in the presence of cross-pollenizers. The results were inconclusive concerning the selffruitfulness of 'Prime-Jim' ${ }^{\circledR}$.

A significant decrease was seen in percent fruit set, drupelet set, and average berry weight of primocane and floricane fruit when comparing cross- and self-pollination with open-pollination in the later-generation $\mathrm{PF}$ genotypes. Although open-pollination repeatedly outperformed cross- and self-pollination, the increases in fruit set, drupelet set, and berry weight could possibly be attributed to negative effects of emasculation, bagging, and/or adverse environmental conditions within bags. It is unknown whether there is a measurable negative effect associated with using protective bags for blackberry pollination studies, but use is recommended in studies in which certainty concerning pollen source is required, like in our study (Finn, 1996; Lopez-Medina and Moore, 2001). Fruit set in almond (Prunus amygadalus Batsch) was significantly reduced when bags were used to cover flowers and developing fruit, and it was speculated that ventilation and light intensity were reduced within bags (Socias i Company et al., 2005). Redalen (1976) found that emasculation significantly reduced fruit set in open-pollinated raspberries, although the cause for reduced fruit set was not investigated. Emasculation accelerated ovule degeneration in sweet cherry (Prunus avium L.), resulting in erratic pollen tube growth and significantly reduced fruit set (Hedhly et al., 2009). Removing leaves within bags may also have had a negative effect by reducing photosynthate availability as a result of loss of leaf area. In corn (Zea mays L.), a reduction in leaf area after detasseling resulted in significant reductions in grain yield. The yield reduction was inversely correlated to the number of leaves removed during detasseling (Wilhelm et al., 1995).

The level of pollen viability in the genotypes included in this study falls within the range of previously reported viability levels for blackberry, including 'Prime-Jim' ${ }^{\circledR}$ and 'Prime-Jan' ${ }^{\circledR}$ (Nybom, 1985, 1986; Stanton, 2005), although APF-31, APF-77, and APF-59 all had significantly more viable pollen than 'Prime-Jan' ${ }^{\circledR}$. Pollen viability ranging from $41 \%$ to $82 \%$ did not appear to be a limiting factor in seed set in blackberries (Nybom, 1986), and the pollen viability range reported in this study was greater than that.

Although significantly more pollen germinated for APF-31, APF-59, and APF-77 than 'Prime-Jim' ${ }^{\circledR}$ and 'Prime-Jan' ${ }^{\circledR}$, all results were lower than expected based on pollen viability. Nybom (1985) reported blackberry pollen germination of $0 \%$ to $25 \%$, whereas pollen viability ranged from $3 \%$ to $56 \%$. Stanton (2005) reported $43 \%$ pollen germination and a range of pollen viability of $64 \%$ to $74 \%$ in PF blackberries. Pollen germination was not correlated to pollen viability, suggesting that the growth media provided suboptimum conditions for germination. Sensitivity to sucrose concentration can result in germination problems, namely reduced germination and burst or shrunken pollen (Kearns and Inouye, 1993). Pollen grains did not appear to have shrunk nor were burst pollen grains observed.

We found stigma receptivity varied little among genotypes, and all genotypes had flowers with nearly all the stigmas receptive. Poor fruit set and reduced fruit quality are not likely related to stigma receptivity in PF blackberries. These findings correspond with other studies evaluating variables related to fruit set, in which a lack of stigma receptivity was seldom noted (Colbert and de Oliveira, 1990; Ledesma and Sugiyama, 2005; Stanton et al., 2007; Werner and Chang, 1981).

Although the fluorescence of pollen tube growth varied among genotype*pollination treatment combinations, pollen tube growth reached the base of the style in photographed pistils for every combination. Therefore, pollen tube growth was not likely inhibited as a result of self-incompatibility in any genotype studied.

Pollen quality was improved in latergeneration genotypes compared with 'Prime Jim' ${ }^{\circledR}$ and 'Prime Jan' ${ }^{\circledR}$ as indicated by greater viability and germination. Enhanced fruit set and quality (measured by drupelet set and berry weight) in APF-31, 'Prime-Ark ${ }^{\circledR}$ 45', APF-59, and APF-77 were noted in the field portion of this study, although the variables leading to fruit set and quality (pollen quality, stigma receptivity, and pollen tube growth) were not measured in the field.

Amplification in male competence will be beneficial to increased commercial adoption of PF blackberries. In the University of Arkansas breeding program, high drupelet set and large fruit size have been primary criteria for selection. The increased fertility seen in 'Prime-Ark ${ }^{\circledR}$ 45', APF-31, APF-59, and APF-77 indicates that breeding and selection can enhance fertility in PF blackberry.

\section{Literature Cited}

Clark, J.R., J.N. Moore, J. Lopez-Medina, C. Finn, and P. Perkins-Veazie. 2005. 'Prime-Jim' ${ }^{\circledR}$ ('APF-8') and 'Prime-Jan' ${ }^{\circledR}(' A P F-12$ ') primocane fruiting blackberries. HortScience 40:852-855.

Colbert, S. and D. de Oliveira. 1990. Influence of pollen variety on raspberry (Rubus idaeus L.) development. J. Hered. 81:434-437.

Daubeny, H.A. 1969. Some variations in self fertility in the red raspberry. Can. J. Plant Sci. 49:511-512.

Daubeny, H.A. 1971. Self fertility in red raspberry cultivars and selections. J. Amer. Soc. Hort. Sci. 96:588-591.

Daubeny, H.A. 1996. Brambles, p. 109-190. In: Janick, J. and J.N. Moore (eds.). Fruit breeding, volume II: Vine and small fruits. John Wiley \& Sons, Inc., New York, NY.

Drake, C. and J.R. Clark. 2003. Effects of pruning and cropping on field-grown primocane fruiting blackberries. HortScience 38: 260-262.

Finn, C. 1996. Emasculated trailing blackberry flowers set some drupelets when not protected from cross-pollination. HortScience 31:1035.

Galletta, G.J. 1983. Pollen and seed management, p. 23-47. In: Moore, J.N. and J. Janick (eds.). Methods in fruit breeding. Purdue Univ. Press, West Layfayette, IN.

Hedhly, A., J.I. Hormaza, and M. Herrero. 2009. Flower emasculation accelerates ovule degeneration and reduces flower set in sweet cherry. Sci. Hort. 119:455-457.

Hellman, E.W. and J.R. Clark. 1984. Blackberry pollen sterility associated with 'Merton Thornless' germplasm. Fruit Var. J. 38:55-57.

Kearns, C.A. and D.W. Inouye. 1993. Techniques for pollination biologists. University of Colorado Press, Niwot, CO.

Keep, E. 1968. Incompatibility in Rubus with special reference to R. idaeus L. Can. J. Genet. Cytol. 10:253-262.

Layne, R.E.C. 1983. Hybridization, p. 48-65. In: Moore, J.N. and J. Janick (eds.). Methods in fruit breeding. Purdue Univ. Press, West Layfayette, IN.

Ledesma, N. and N. Sugiyama. 2005. Pollen quality and performance in strawberry plants exposed to high-temperature stress. J. Amer. Soc. Hort. Sci. 130:341-347.

Lopez-Medina, J. and J.N. Moore. 2001. Drupelet set on 'Arapaho' thornless blackberry flowers protected and nonprotected from crosspollination and assessment of resulting seedlings. HortScience 36:174.

Nybom, H. 1985. Pollen viability assessments in blackberries (Rubus L subgen. Rubus). Plant Syst. Evol. 150:281-290.

Nybom, H. 1986. Active self-pollination and pollen stainability in some Rubus cultivars. J. Hort. Sci. 61:49-55.

Perry, J.L. 1981. Self and cross-compatibility of tetraploid blackberry cultivars (Rubus subgenus Eubatus). MS Thesis, Univ. of Ark., Fayetteville, AR.

Perry, J.L. and J.N. Moore. 1985. Self- and crosscompatibility in tetraploid blackberry cultivars. HortScience 20:738-739.

Redalen, G. 1976. Pollination and fruit set in raspberries. Acta Hort. 60:169-173.

SAS Institute. 2008. SAS/STAT software. Version 9.2. SAS Institute, Cary, NC. 
Socias i Company, R.J. Gomez Aparisi, and J.M. Alonso. 2005. Year and enclosure effects on fruit set in an autogamous almond. Sci. Hort. 104:369-377.

Stanton, M.A. 2005. The effects of heat on flowering and fruiting of two primocane-fruiting cultivars of blackberry, Rubus spp., 'PrimeJan' ${ }^{\circledR}$ and 'Prime-Jim' ${ }^{\circledR}$. MS Thesis, The Ohio State University, Columbus, $\mathrm{OH}$.
Stanton, M.A., J.C. Scheerens, R.C. Funt, and J.R. Clark. 2007. Floral competence of primocane fruiting blackberries 'PrimeJan' ${ }^{\circledR}$ and 'Prime-Jim' ${ }^{\circledR}$ grown at three temperature regimens. HortScience 42: 508-513.

University of Arkansas. 2010. Commercial horticulture-Fruits and nuts. Prime-Ark ${ }^{\circledR}$ 45 primocane-fruiting blackberry. 5 May
2010. <http://www.aragriculture.org/horticulture/ fruits_nuts/Blackberries/prime_ark45.htm>.

Werner, D.J. and S. Chang. 1981. Stain testing viability in stored peach pollen. HortScience 16:522-523.

Wilhelm, W.W., B.E. Johnson, and J.S. Schepers. 1995. Yield, quality, and nitrogen use of inbred corn with varying numbers of leaves removed during detasseling. Crop Sci. 35:209-212. 